\title{
Entada (Leguminosae, Mimosoideae) em Roraima, Brasil
}

\author{
Entada (Leguminosae, Mimosoideae) in Roraima, Brazil
}

Elivane dos Santos Braga ${ }^{1}$, Gildo Vieira Feitoza ${ }^{2}$, Andréia Silva Flores ${ }^{3}$ \& Rodrigo Schütz Rodrigues ${ }^{1,4}$

\begin{abstract}
Resumo
Entada é um gênero pantropical de Leguminosae (Mimosoideae) com 28 espécies. Este trabalho apresenta o estudo taxonômico de Entada para o estado de Roraima, norte do Brasil. Três táxons de Entada foram reconhecidos em Roraima, aqui tratados como espécies distintas: E. polyphylla, E. polystachya e E. simplicata. São apresentadas chave de identificação, descrições e ilustrações, bem como informações sobre distribuição geográfica, ambientes preferenciais e dispersão das espécies. O endemismo de E. simplicata e o primeiro registro de E. polyphylla fazem com que Roraima seja, até o momento, o único estado onde ocorrem todas as espécies de Entada registradas para o Brasil.
\end{abstract}

Palavras-chave: Amazônia, Fabaceae, Mimoseae, taxonomia.

\begin{abstract}
Entada is a pantropical legume genus (Leguminosae, Mimosoideae) with 28 species. This paper presents a taxonomic survey of Entada in Roraima state, north Brazil. Three Entada taxa have been recognized in Roraima, treated here as separate species: E. polyphylla, E. polystachya and E. simplicata. An identification key, descriptions, illustrations, as well as information on geographic distribution, habitats and dispersion, are also provided. Both the endemism of E. simplicata and the first record of E. polyphylla make Roraima the only state where all species of Entada recorded in Brazil occur.
\end{abstract}

Key words: Amazonia, Fabaceae, Mimoseae, taxonomy.

\section{Introdução}

Entada Adans. está inserido em Leguminosae, subfamília Mimosoideae, tribo Mimoseae (Luckow 2005). Suas espécies abrangem arbustos, arvoretas apoiantes ou lianas inermes, das quais algumas são utilizadas na produção de lenha, carvão, joias e como cobertura vegetal ou possuem potencial medicinal (Luckow 2005; Priya \& Rao 2008; Zheng et al. 2012; Nzowa et al. 2013).

Entada apresenta distribuição pantropical e compreende 28 espécies, com maior riqueza documentada na África tropical (Luckow 2005). Na região Neotropical, quatro táxons de Entada ocorrem desde o México, América Central e Caribe até a América do Sul tropical (Barneby 1996; Forero \& Romero 2009). Estes táxons pertencem a duas seções: E. sect. Entada [E. gigas (L.) Fawc. \& Rendle] e E. sect. Entadopsis (Britton) Brenan [E. polyphylla Benth., E. polystachya (L.) DC. e E. simplicata (Barneby) Sch. Rodr. \& A.S. Flores].

No Brasil foram registrados somente os três táxons de Entada sect. Entadopsis (Barneby 1996; BFG 2015), que apresentam frutos cartáceos e sementes pleurogramáticas, relativamente pequenas (até $20 \mathrm{~mm}$ de diâmetro) (Brenan 1966; Forero \& Romero 2009). Desde suas descrições originais, tanto $E$. polystachya como E. polyphylla foram consideradas como espécies distintas por vários autores (e.g., Bentham 1876; Macbride 1943; Brenan 1966). Entretanto, a partir do trabalho de Barneby (1996), a circunscrição dos táxons em $E$. sect.

\footnotetext{
${ }^{1}$ Universidade Federal de Roraima, Centro de Estudos da Biodiversidade, Av. Cap. Ene Garcez 2413, Aeroporto, 69310-000, Boa Vista, RR, Brasil.

${ }^{2}$ Universidade Estadual de Roraima, R. 7 de Setembro 231, Canarinho, Boa Vista, 69306-530, RR, Brasil.

${ }^{3}$ Instituto de Amparo à Ciência, Tecnologia e Inovação do estado de Roraima (IACTI), Museu Integrado de Roraima, Herbário MIRR, Av. Brigadeiro Eduardo Gomes 1128, Boa Vista, 69330-640, RR, Brasil.

${ }^{4}$ Autor para correspondência: rodrigo.schutz@ufrr.br
} 
Entadopsis vem sendo controversa. Barneby (1996) tratou todos os táxons de E. sect. Entadopsis como uma única espécie, por considerar uniformes as suas inflorescências, flores e demais estruturas reprodutivas. Assim, Barneby (1996) circunscreveu E. polystachya com três variedades: E. polystachya var. polystachya, E. polystachya var. polyphylla (Benth.) Barneby e E. polystachya var. simplicata Barneby, esta última descrita a partir de uma única coleta em flor procedente de Roraima, norte do Brasil.

Desde então, a delimitação de Barneby (1996) tem sido aceita por alguns autores (e.g., Luckow 2005; Barneby 2011; BFG 2015), enquanto outros permaneceram reconhecendo Entada polyphylla como uma espécie distinta de E. polystachya (Procópio et al. 1999; Barneby 2001; Grimes 2002; Forero \& Romero 2009). Cabe ressaltar que, após o falecimento de Barneby em 2000, seus dois tratamentos florísticos póstumos sobre Entada divergiram quando à aceitação (Barneby 2001) ou não (Barneby 2011) de E. polyphylla em nível específico.

Mais recentemente, estudos taxonômicos e morfológicos comparativos foram conduzidos para avaliar o complexo dos três táxons infraspecíficos de E. polystachya. Por um lado, E. simplicata foi considerada como uma espécie distinta, tendo em vista a constatação de caracteres diagnósticos em seus frutos, sementes e plântulas, além do número de pares e largura dos foliólulos (Rodrigues \& Flores 2012; Rodrigues et al. 2014). Por outro lado, estudos sobre sementes (Rodrigues 2015a) e plântulas de E. polyphylla (Rodrigues 2015b) têm dado suporte ao seu restabelecimento em nível específico.

Em Roraima, duas espécies de Entada foram registradas, E. polystachya e E. simplicata (Rodrigues \& Flores 2012). Entretanto, até o momento, ambas as espécies ainda são pouco representadas nos herbários de Roraima, não existindo descrições detalhadas disponíveis para os táxons no Estado. O presente estudo teve como objetivo realizar o tratamento taxonômico de Entada em Roraima, incluindo chave de identificação, descrições e ilustrações, bem como informações sobre distribuição geográfica e ambientes preferenciais das espécies.

\section{Material e Métodos}

Foi realizada uma análise morfológica de exsicatas dos herbários INPA, MG, MIRR, RB e UFRR, juntamente com imagens digitais de exsicatas do herbário NY. Excursões foram realizadas em diferentes municípios de Roraima para coleta, registro fotográfico e observações de espécimes em campo. Os exemplares coletados foram incorporados aos herbários MIRR e/ ou UFRR. As descrições do gênero e das espécies foram elaboradas com base na variação morfológica dos espécimes de Roraima, sendo também utilizadas as informações presentes nas etiquetas das exsicatas e de observações de campo. Os dados sobre a distribuição geográfica e os habitats preferenciais das espécies foram obtidos através de informações constantes nas etiquetas das exsicatas e de observações de campo, complementadas com as da literatura. As medidas dos pecíolos e peciólulos incluem as dos pulvinos e pulvínulos, respectivamente. Descrições detalhadas da morfologia da semente e da plântula das espécies estão disponíveis em Rodrigues et al. (2014) e Rodrigues (2015a; 2015b).

\section{Resultados e Discussão}

Foram encontradas três espécies de Entada em Roraima (Figs. 1; 2), das quais E. polyphylla Benth. constitui nova ocorrência para a flora do Estado. As espécies E. polystachya e $E$. simplicata foram confirmadas para Roraima, ambas já mencionadas anteriormente na literatura consultada (e.g., Barneby 1996; Rodrigues \& Flores 2012).

Considerando as expressivas diferenças encontradas na morfologia de sementes, frutos e plântulas destas três espécies, este trabalho reconhece aqui $E$. polyphylla como uma espécie distinta, concordando com vários tratamentos anteriores (Bentham 1876; Macbride 1943; Brenan 1966; Procópio et al. 1999; Barneby 2001; Grimes 2002; Forero \& Romero 2009; Rodrigues 2015b).

\section{Tratamento taxônomico}

Entada Adans., Fam. P1. 2: 318. 1763, nom. cons. Entadopsis Britton \& Rose, N. Amer. F1. 23: 191. 1928.

Arvoretas apoiantes ou lianas inermes. Estípulas lanceoladas a linear-lanceoladas, cedo caducas. Folhas alternas, bipinadas (Fig. 1a,c,g), sem nectários peciolares; gavinhas ocasionalmente presentes, lenhosas, modificadas a partir da raque de folíolos terminais (Fig. 1f). Panículas terminais de racemos espiciformes (Fig. 1a,c,d); bráctea floral linear-lanceolada, caduca. Flores pentâmeras, glabras, subsésseis, 

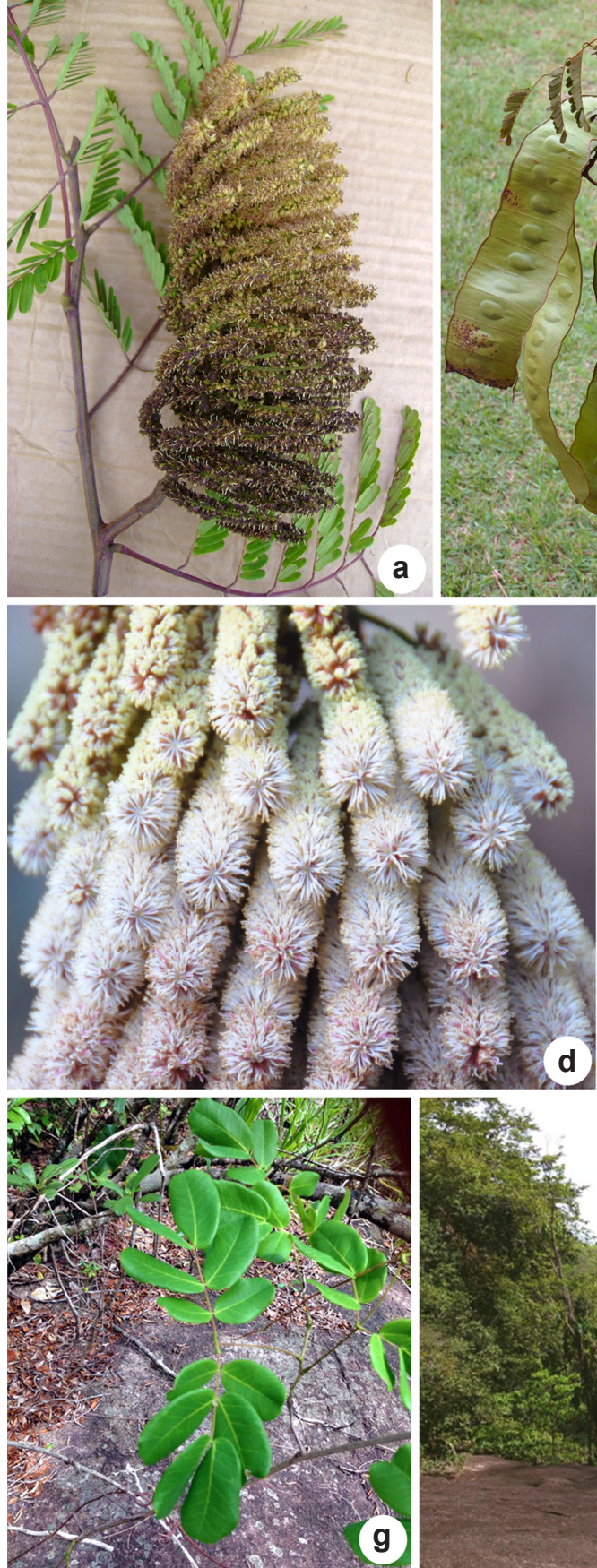
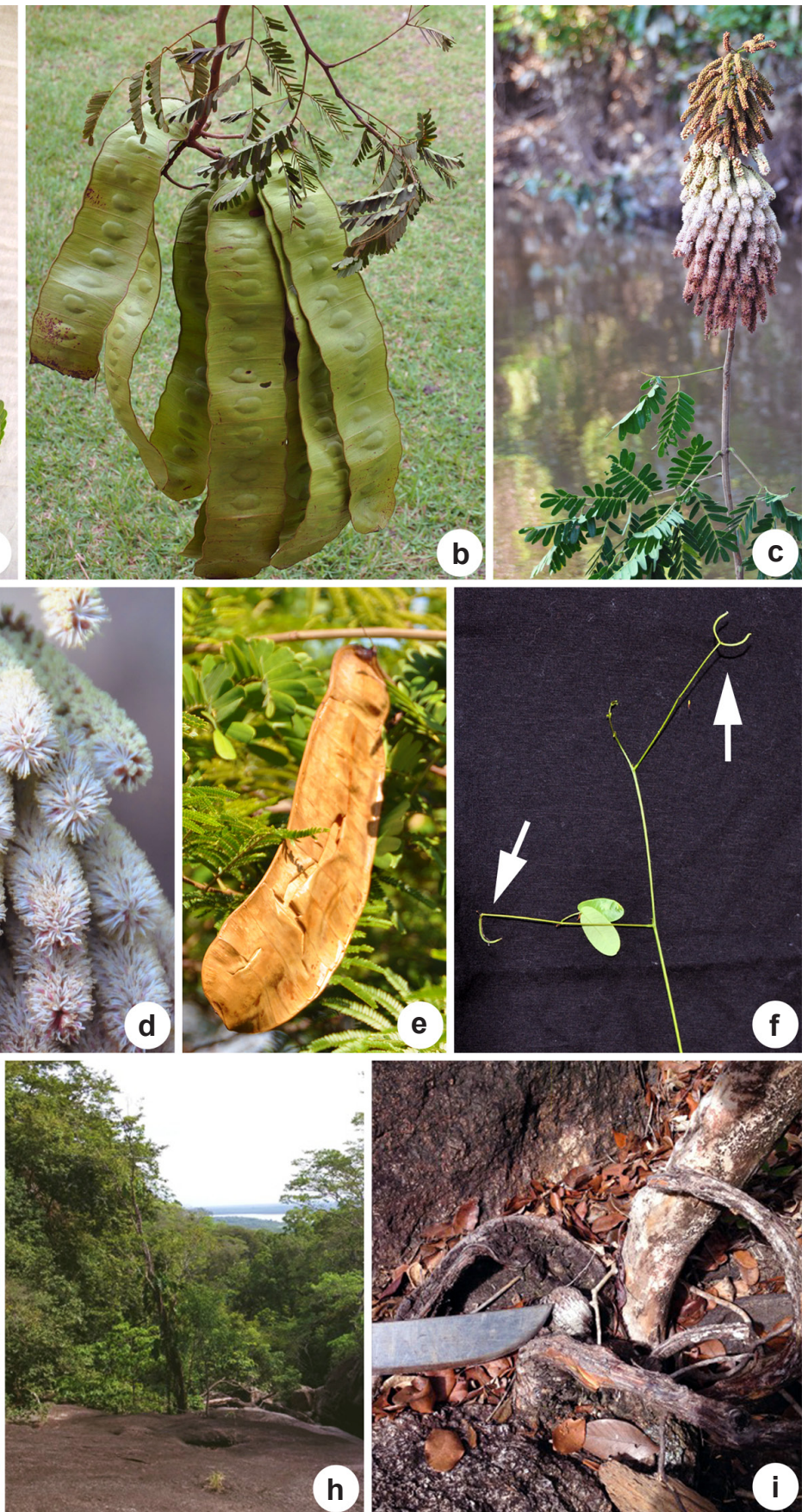

Figura 1 - Entada (Leguminosae) em Roraima, Brasil-a-b. E. polyphylla - a. ramo com flores; b. ramo com frutos imaturos. c-e. E. polystachya - c. ramo com flores; d. detalhe dos racemos espiciformes; e. ramo com frutos maduros. f-g. E. simplicata - f. indivíduo jovem (ca. 8 meses), com a raque dos folíolos terminais modificada em gavinhas; g. ramo com folhas. h-i. ambiente de ocorrência de E. simplicata na Serra Grande, município do Cantá - h. borda de floresta tropical de encosta, em meio a afloramentos rochosos graníticos; i. detalhe de um indivíduo em uma fenda entre dois matacões de granito. Crédito das fotos: a. Christiane Silva da Costa; b,e. Andréia Silva Flores; c-d,f. Rodrigo Schütz Rodrigues; g-i. Ricardo de Oliveira Perdiz. Figure 1 - Entada (Leguminosae) in Roraima, Brazil-a-b. E. polyphylla -a. flowering branch; b. fruiting branch (imature pods). c-e. E. polystachya - c. flowering branch; d. detail of the spiciform racemes; e. fruiting branch. f-g. E. simplicata - f. sapling (ca. 8 months), with the rachis of terminal leaflets modified in tendrils; g. leafy branch. h-i. habitat of E. simplicata (Serra Grande, Cantá municipality) - h. edge of tropical slope forest, with granite outcrops; i. detail of a specimen growing between two granite rocks. Photo credits: a. Christiane Silva da Costa; b,e. Andréia Silva Flores; c-d,f. Rodrigo Schütz Rodrigues; g-i. Ricardo de Oliveira Perdiz. 
com pedicelo $0,2-0,3 \mathrm{~mm}$ compr.; cálice gamossépalo, creme-esverdeado a vináceo, campanulado, lacínias com ápice agudo, menores que o tubo; corola dialipétala, pétalas vináceas a castanho-avermellhadas, elípticas, ápice agudo a acuminado; androceu dialistêmone, estames 10, filetes brancos, anteras creme, com glândulas caducas no ápice; gineceu 1-carpelar, ovário linear, séssil, 15-20 óvulos, estigma tubular. Frutos craspédios, indeiscentes, separandose em artículos 1-seminados livres do replo, cartáceos, achatados, oblongos a levemente falcados (Figs. 1b,e; 2a-d), base assimétrica abruptamente atenuada e ápice arredondado a truncado, margens ventral e dorsal onduladas a retas; artículos com câmaras seminíferas visíveis, reticuladamente nervados, com epicarpo exfoliante. Mesocarpo inconspícuo (Fig. 2e,g) ou relativamente desenvolvido (Fig. 2f), esponjoso. Sementes oblongas a elípticas, achatadas, simétricas, unisseriadas; testa marrom, cartácea, com pleurograma (auréola 90-100\%); hilo punctiforme, apical, sem arilo; endosperma ausente; embrião com cotilédones oblongos a elípticos, com base lobada e ápice arredondado.

\section{Chave de Identificação para as espécies de Entada do estado de Roraima}

1. Folíolos com 1-3 pares de foliólulos; maiores foliólulos $\geq 30 \mathrm{~mm}$ larg.; frutos $\leq 5,3 \mathrm{~cm}$ larg.

3. Entada simplicata

1'. Folíolos com 7-16 pares de foliólulos; maiores foliólulos $\leq 17 \mathrm{~mm}$ larg.; frutos $\geq 5,6 \mathrm{~cm}$ larg..........2

2. Folíolos com 10-16 pares de foliólulos; maiores foliólulos $\leq 5,5 \mathrm{~mm}$ larg.; frutos com mesocarpo inconspícuo

1. Entada polyphylla

2'. Folíolos com 7-10 pares de foliólulos; maiores foliólulos $\geq 8 \mathrm{~mm}$ larg.; frutos com mesocarpo esponjoso 2. Entada polystachya
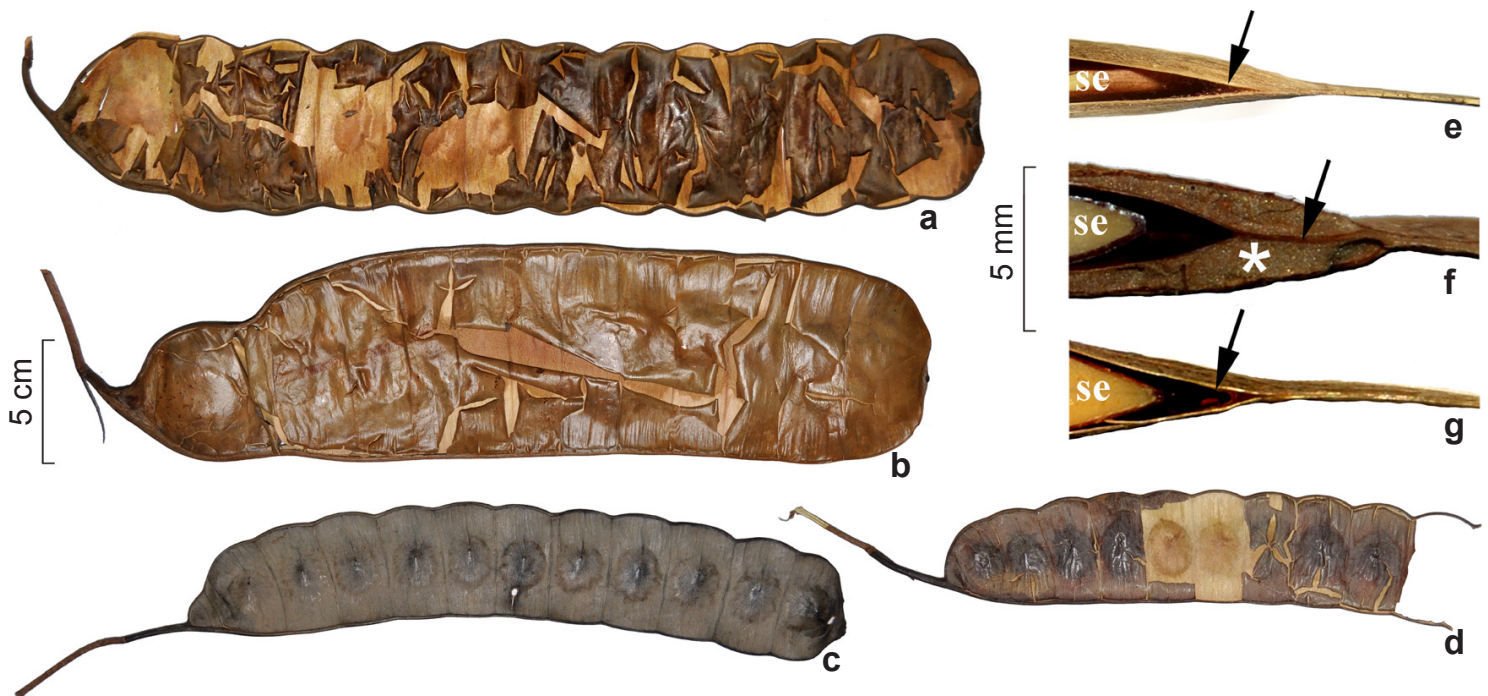

Figura 2 - Frutos das espécies de Entada (Leguminosae) em Roraima, Brasil -a. E. polyphylla. b. E. polystachya. c-d. E. simplicata. e-g. corte transversal de um artículo, evidenciando parcialmente uma semente (se), o núcleo seminífero e a ala (setas indicando o endocarpo e o asterisco o mesocarpo esponjoso) - e. E. polyphylla; f. E. polystachya; g. E. simplicata. Escalas: a-d = 5 cm; e-g $=5$ mm (a,e. Braga et al. 73; b. Schütz Rodrigues et al. 2129; c-d,g. Flores \& Peixoto 2147; f. Flores et al. 2469). Fotos: Rodrigo Schütz Rodrigues.

Figure 2 - Fruits of Entada species (Leguminosae) in Roraima, Brazil -a. E. polyphylla. b. E. polystachya. c-d. E. simplicata. e-g. longitudinal section of a fruit segment, partially showing a seed (se), the seed chamber and the wing (arrows indicating the endocarp and the asterisk the spongy mesocarp) - e. E. polyphylla; f. E. polystachya; g. E. simplicata. Scale bars: a-d = $5 \mathrm{~cm}$; e-g $=5 \mathrm{~mm}$ (a,e. Braga et al. 73 ; b. Schütz Rodrigues et al. 2129; c-d,g. Flores \& Peixoto 2147; f. Flores et al. 2469). Photos: Rodrigo Schütz Rodrigues. 
1. Entada polyphylla Benth., J. Bot. (Hooker) 2: 133. 1840. Iconografia: Bentham (1876: prancha 70), Procópio et al. (1999:365, 381), Forero \& Romero (2009:75).

Figs. 1a-b;2a,e

Arvoretas apoiantes, 2-6 $\mathrm{m}$ alt.; ramos castanhos, glabros a puberulentos. Estípulas 0,9-1,4 mm compr. Pecíolo 2,8-3,4 cm compr., adaxialmente canaliculado; raque $3,5-8 \mathrm{~cm}$ compr., ráquila 3,3-6 cm compr., ambas similares ao pecíolo; peciólulos $0,5-0,8 \mathrm{~mm}$ compr.; folíolos em 5-6 pares; foliólulos em 10-16 pares, os maiores foliólulos 12-18 × 3-5,5 mm, elíptico-oblongos a obovados, base assimétrica, arredondada-cuneada, ápice retuso a truncado-arredondado, ambas as faces puberulentas. Raque da inflorescência 15-25 cm compr.; bráctea floral 0,5-1 mm compr. Cálice com tubo 0,5-0,7 mm compr., lacínias 0,2-0,3 mm compr.; pétalas 2,1-2,9 ×0,6-0,9 mm; estames com filetes 2,2-3,5 mm compr., anteras $0,4-0,7 \times 0,4-0,5$ $\mathrm{mm}$; carpelo 3,5-4,3 × 0,4-0,5 mm. Frutos 27-47,5 $\times 5,6-7,2 \mathrm{~cm}$, estípite $13-25 \mathrm{~mm}$ compr., ambas as margens onduladas, epicarpo castanho; mesocarpo inconspícuo. Sementes 19-24,2 × 10-12 mm.

Material examinado: Caracaraí, Boca do Rio Branco, 18.III.2012, fl. e fr., R.C. Forzza et al. 6796 (MIRR, RB). Caroebe, Vicinal 06, 24.X.2007, fl., C.S. Costa \& O. Grigio Jr. 150 (MIRR); Vicinal 03, 27.II.2014, fr., E.S. Braga et al. 73 (MIRR); Vicinal 04, 26.VI.2013, est., A.S. Flores et al. 2675 (MIRR). São João da Baliza, Vicinal 24, 27.II.2014, fr., E.S. Braga et al. 74 (MIRR).

Entada polyphylla ocorre em Porto Rico, Equador, Peru, Venezuela, Guiana, Suriname, Guiana Francesa e Brasil (Acre, Amazonas, Pará) (Barneby 1996, 2001, 2011; Caraballo-Ortiz 2013; BFG 2015). Em Roraima, foi encontrada em borda de floresta tropical de terra firme em municípios do sul do Estado.

Além das características mencionadas na chave, E. polyphylla distingue-se das espécies de Entada em Roraima por caracteres dos embriões e plântulas. Dentre as principais diferenças, os embriões de E. polyphylla apresentam pecíolos cotiledonares desenvolvidos, lobos cotiledonares assimétricos e eixo hipocótilo-radícula exposto (Rodrigues 2015a). Por sua vez, E. polystachya e E. simplicata têm pecíolos cotiledonares inconspícuos, lobos cotiledonares simétricos e eixo hipocótiloradícula parcialmente encoberto pelos lobos cotiledonares (Rodrigues et al. 2014). Com relação às plântulas, E. polyphylla se destaca por apresentar plântulas criptocotiledonares, enquanto que E. polystachya e E. simplicata possuem plântulas fanerocotiledonares (Rodrigues et al. 2014; Rodrigues 2015b).
Em adição, as margens dos frutos podem contribuir para distinguir E. polyphylla (margens onduladas, Figs. 1b, 2a) de E. polystachya (margens retas a ligeiramente onduladas, Figs. 1e; 2b).

2. Entada polystachya (L.) DC, Prodr. 2: 425. 1825. Iconografia: Woodson \& Schery (1950:311), Luckow (2005:169), Forero \& Romero (2009:75), Barneby (2011:72).

Figs. 1c-e;2b,f

Arvoretas apoiantes ou lianas, 2-10 m alt.; ramos castanhos, glabros a pubescentes. Estípulas 1,3-1,8 mm compr. Pecíolo 3,6-6,9 cm compr., adaxialmente canaliculado; raque (1,9-) 2,7-12 cm compr., ráquila $(2,4-)$ 4,5-10,5 cm compr., ambas similares ao pecíolo; peciólulos 0,7-1,5 mm compr.; folíolos em (2-) 3-5 pares; foliólulos em 7-10 pares, os maiores foliólulos 25-40 × 8-17 mm, obovados a elíptico-oblongos, base assimétrica, arredondadacuneada, ápice retuso a arredondado, ambas as faces glabras a puberulentas, mais densamente ao longo da nervura principal. Raque da inflorescência 20-61,5 cm compr.; bráctea floral (0,4-) 1,1-1,5 mm compr. Cálice com tubo 0,3-0,7 mm compr., lacínias 0,20,3 mm compr.; pétalas 2,2-3,2 ×0,9-1 mm; estames com filetes 1,3-3,9 mm compr., anteras 0,5-0,7 $\times$ 0,4-0,6 mm; carpelo 2,4-5,5 × 0,3-0,6 mm. Frutos (12,5-) 19-34 × 5,7-9,3 cm, estípite 10-25 mm compr., ambas as margens inteiras a ligeiramente onduladas, epicarpo castanho; mesocarpo esponjoso. Sementes 15-17,2 × 9-11 mm.

Material examinado: Alto Alegre, SEMA, Ecological Reserve Ilha de Maracá, 04.V.1987, fr., W. Milliken et al. 168 (INPA, MIRR, NY,); 10.IV.1987, fl., W. Milliken 63 (INPA, MIRR, NY); 27.II.1987, est., J.A. Ratter et al. 5500 (INPA); Rio Uraricoera, 09.III.1987, fl., G.P. Lewis 1432 (INPA, MIRR, NY); 19.II.1979, fr., J.M. Pires et al. 16746 (INPA, MG); 26.II.1988, fr., L. Augusto 600 (INPA); Rio Mucajaí, 01.VIII.1986, fl., M.R. Barbosa 910 (INPA, MIRR); Vicinal 01 em direção ao Rio Mucajaí, 09.IX.2009, fl., A.S. Flores et al. 2363 (MIRR); Vicinal 04, 09.IX.2009, fl., A.S. Flores et al. 2360 (MIRR); aterro da estrada que dá acesso à Estação através do campo alagado na várzea do rio Uraricoera, 23.IV.1987, M.F. da Silva et al. 2380 (INPA). Boa Vista, Orla Taumanan, 18.VIII. 2009, fr., R. Schütz Rodrigues et al. 2129 (MIRR); 26.IV.2007, fr., A.S. Flores et al. 2002 (MIRR); margem direita do Rio Cajual, 12.XI.1991, fl., E. Sette-Silva et al. 2143 (MIRR); Bonfim, Zona Rural, sítio Fazendinha, 11.XI.2012, fr., R.O. Perdiz \& N.P. Smith 1655 (MIRR); fl., R.O. Perdiz \& N.P. Smith 1654 (MIRR). Caracaraí, Parque Nacional da Mocidade, Rio Capivara, 08.XII. 2013, fl., R. Schütz Rodrigues et al. 2439 (MIRR, UFRR); BR 174 em direção a Boa Vista, 28.V.2010, fr., A.S. Flores et al. 2469 (MIRR); Parque Nacional do Viruá, na estrada do rio Barauana, 18.I.2011, fr., F.N. Cabral et al. 349 
(INPA, UFRR); Várzea do Rio Barauana, 15.IX.2010, fl., A.R. Lourenço et al. 377 (INPA, UFRR); Borda do rio Barauana, 26.VII.2010, fl., M.V. Martins et al. 160 (INPA, UFRR); Rio Catrimani, $15 \mathrm{~km}$ acima da boca do Rio Branco, 25.III.2012, fl., G. Martinelli et al. 17485 (RB). Iracema, Estrada Apiaú, 19.XI.2008, fr., A.S. Flores \& F.C. Peixoto 2137 (MIRR); Cachoeira do Roxinho, 06.XII. 2014, R. Schütz Rodrigues et al. 2744 (MIRR). Mucajaí, Vicinal tronco, ca. $20 \mathrm{~km}$ do Roxinho, 18.V.2007, fr., R. Schütz Rodrigues et al. 1846 (MIRR); Canta Galo, Rio Mucajaí, 22.I.1967, fr., G.T. Prance et al. 4003 (INPA, MG, NY).

Entada polystachya ocorre desde o oeste do México, América Central, Porto Rico e Caribe, até a América do Sul, do norte da Colômbia, Venezuela, Guiana, Suriname, Guiana Francesa ao norte da Bolívia e Brasil (Acre, Amapá, Amazonas, Maranhão, Mato Grosso, Pará, Rondônia, Roraima) (Barneby 1996, 2001, 2011; BFG 2015). Em Roraima ocorre principalmente em borda de mata ciliar (Fig. 1c). Entada polystachya ocorre simpatricamente com E. simplicata na região da Cachoeira do Roxinho, no município de Iracema, onde ambas habitam bordas de florestas em meio a afloramentos graníticos. Nesta localidade, observações de campo não detectaram a ocorrência de indivíduos com características vegetativas e/ou reprodutivas intermediárias entre as duas espécies.

Além das características mencionadas na chave, testa com linhas de fratura, eixo hipocótiloradícula bulboso, longo ( $\geq 3,7 \mathrm{~mm}$ compr.) e plântulas epígeas são alguns dos caracteres diagnósticos evidenciados nas sementes e plântulas de E. polystachya (Rodrigues et al. 2014). Por outro lado, tanto $E$. polyphylla quanto $E$. simplicata apresentam testa sem linhas de fratura, eixo hipocótilo-radícula triangular, curto $(\leq 2,7 \mathrm{~mm}$ compr.) e plântulas hipógeas (Rodrigues et al. 2014; Rodrigues 2015a, 2015b).

3. Entada simplicata (Barneby) Sch. Rodr. \& A. S. Flores, Phytotaxa 39: 47. 2012. Iconografia: Rodrigues \& Flores (2012:48).

Figs. 1f-i;2c-d,g

Arvoretas apoiantes, 2-5 m alt.; ramos castanhos, glabros a pubescentes. Estípulas 1,8-3 mm compr. Pecíolo 3,7-7,7 cm compr., adaxialmente canaliculado; raque $5,8-13 \mathrm{~cm}$ compr., ráquila 1,6-3,7 cm compr., ambas similares ao pecíolo; peciólulos 1,5-3 $\mathrm{mm}$ compr.; folíolos em 1-3 pares; foliólulos em 1-3 pares, os maiores foliólulos 45-83 × 30-52 mm, obovados a largamente elípticos, base assimétrica, arredondadacuneada, ápice retuso a truncado, ambas as faces glabras. Raque da inflorescência 16-26 cm compr.; bráctea floral 1-1,2 mm compr. Cálice com tubo 0,6-0,8 mm compr., lacínias 0,3-0,4 mm compr.; pétalas 2,2-3,2 × 0,9-1 mm; estames com filetes 3,8-4,5 mm compr., anteras $0,4-0,6 \times 0,3-0,5$ $\mathrm{mm}$; carpelo 3,7-5 × 0,4-0,7 mm. Frutos 25,5-29 $\times$ 3,8-5,3 cm; estípite $25-36 \mathrm{~mm}$ compr., margem ventral ondulada, a dorsal ligeiramente ondulada, epicarpo acinzentado; mesocarpo inconspícuo. Sementes 14-20 × 9-13 mm.

Material examinado: Cantá, Serra Grande, 03.V.2014, est., R. Schütz Rodrigues \& R.O. Perdiz 2686 (UFRR). Caracaraí, Estrada Perimetral Norte, $10 \mathrm{~km}$ do entroncamento com estrada Manaus-Caracaraí, 23.VIII.1987, C.A. Cid Ferreira 9220 (INPA, MIRR, NY, UFRR). Iracema, Cachoeira do Roxinho, 14.IX.2002, fl., L.A. Pessoni \& A.J.R. Silva 639 (UFRR); 21.VIII.2002, fl., L.A. Pessoni 574 (UFRR); 19.XI.2008, fr., A.S. Flores \& F.C. Peixoto 2147 (MIRR).

Entada simplicata é uma espécie endêmica de Roraima, sendo encontrada em florestas tropicais de encosta, em meio a afloramentos rochosos graníticos (Fig. 1h-i), ou em margens de florestas abertas. Entada simplicata é vegetativamente distinta de E. polyphylla e E. polystachya pela sua peculiar morfologia foliar, pois seus foliólulos são relativamente maiores e em menor número (Fig. $1 \mathrm{~g})$. Além disso, vários caracteres reprodutivos como largura dos frutos, cor do epicarpo (Fig. 2a-d) e alguns outros caracteres de sementes e plântulas são taxonomicamente úteis para distinguir E. simplicata das outras duas espécies ocorrentes em Roraima (Rodrigues et al. 2014; Rodrigues 2015a, 2015b).

\section{Habitats e dispersão}

Em Roraima, E. polystachya é a espécie mais amplamente distribuída, sendo encontrada principalmente em borda de matas ripárias, tanto de pequenos igarapés quanto de rios de maior envergadura, como os rios Mucajaí, Uraricoera e Branco. Em adição, ocorre ocasionalmente em bordas de florestas em meio a afloramentos graníticos.

Leguminosae é uma das principais famílias ocorrentes na Amazônia cujo agente de dispersão é a água pois apresentam frutos com evidentes mecanismos para flutuação, como pericarpos espessos, leves e esponjosos (Kubitzki 1985; Lima 1990). Isto também é evidenciado em Entada polystachya, que possui o mesocarpo esponjoso do núcleo seminífero relacionado com a dispersão hidrocórica (Barroso et al. 1999). Por outro lado, estudos experimentais relataram que 
a dispersão de E. polystachya pode ser também funcionalmente anemocórica (Pounden et al. 2008). De fato, a hidrocoria não exclui a dispersão por outros agentes, mas pode ser combinada com a anemocoria, de acordo com observações de algumas espécies amazônicas (Ferreira et al. 2010). Isto nos leva a crer, de acordo com os seus ambientes preferenciais, que E. polystachya disperse seus artículos unisseminados tanto pela água quanto pelo vento, o que já foi sugerido anteriormente por Lewis \& Owen (1989).

Por outro lado, Entada polyphylla e E. simplicata têm frutos com pericarpo relativamente mais delgado cujo mesocarpo é inconspicuamente desenvolvido. Segundo Lima (1990), estas características são compatíveis com a anemocoria, conforme observações feitas em táxons de Leguminosae da tribo Dalbergieae. Estas duas espécies não ocorrem em borda de matas ripárias em Roraima, sendo encontradas principalmente em bordas de florestas de terra firme ou em florestas de encosta. Desta forma, é possível que E. polyphylla e E. simplicata dispersem seus frutos exclusivamente pelo vento. Porém, considerando que não há indicação na literatura sobre sua dispersão, sugerem-se estudos sobre as estratégias reprodutivas dos táxons de Entada ocorrentes em Roraima.

Como conclusão, a análise morfológica aqui desenvolvida, em associação com estudos adicionais sobre sementes e plântulas, permitiu o reconhecimento de três táxons de Entada em Roraima, aqui tratados como espécies distintas. O endemismo de E. simplicata e o primeiro registro de E. polyphylla fazem com que Roraima seja, até o momento, o único estado onde ocorrem todas as espécies de Entada citadas para o Brasil.

\section{Agradecimentos}

Os autores agradecem aos dois revisores anônimos, as correções e sugestões. A Christiane Silva da Costa e Ricardo de Oliveira Perdiz, por permitirem a publicação de suas fotografias. A Christiane Silva da Costa e Octaviano Grigio Jr., o valioso auxílio durante as coletas. Ao Programa de Iniciação Científica PIC-UFRR (EDITAL 01/2013-PIC/PRPPG), a bolsa PIBIC/CNPq para a primeira autora. Ao Instituto de Amparo à Ciência, Tecnologia e Inovação do Estado de Roraima (IACTI)/Museu Integrado de Roraima (MIRR), o apoio durante as excursões de coletas. Ao Centro de Estudos da Biodiversidade (CBio/UFRR), as facilidades para o desenvolvimento do trabalho.

\section{Referências}

Barneby, R.C. 1996. Neotropical fabales at NY: asides and oversights. Brittonia 48: 174-187.

Barneby, R.C. 2001. Entada Adans. In: Berry, P.E.; Yatskievych, K. \& Holst, B.K. (eds.). Flora of the Venezuelan Guayana. Vol. 6. Missouri Botanical Garden Press, St. Louis. Pp. 610-611.

Barneby, R.C. 2011. Entada.In: Barneby, R.C.; Grimes, J.W. \& Poncy, O. (eds.). Flora of the Guianas. A 28. Royal Botanic Gardens, Kew. Pp. 71-75.

Barroso, G.M.; Morim, M.P.; Peixoto, A.L. \& Ichaso, C.L.F. 1999. Frutos e sementes: morfologia aplicada à sistemática de dicotiledôneas. Editora UFV, Viçosa. 443p.

Bentham, G. 1876. Entada. In: Martius, C.F.P. \& Eichler, A.G. (eds.). Flora Brasiliensis. F. Fleischer, Lipsiae. Vol. 15, pars 2, pp. 268-270.

BFG. 2015. Growing knowledge: an overview of Seed Plant diversity in Brazil. Rodriguésia 66: 1085-1113.

Brenan, J.P.M. 1966. Notes on Mimosoideae. XI: the genus Entada, its subdivisions and a key to the African species. Kew Bulletin 20: 361-378.

Caraballo-Ortiz, M.A. 2013. Rediscovery of Arrabidaea chica (Bignoniaceae) and Entada polystachya var. polyphylla (Fabaceae) in Puerto Rico. Phytotaxa 125: 53-58.

Ferreira, C.S.; Piedade, M.T.F.; Wittmann, A. de O. \& Franco, A.C. 2010. Plant reproduction in the Central Amazonian floodplains: challenges and adaptations. AoB Plants 2010: 1-14. DOI: 10.1093/ aobpla/plq009

Forero, E. \& Romero, C. 2009. Sinopsis de las Leguminosae: Mimosoideae de Colombia. In: Forero, E. (ed.). Estudios en leguminosas colombianas II. Instituto de Ciencias Naturales, Universidad Nacional de Colombia, Bogotá. Pp. 9-235.

Grimes, J.W. 2002. Mimosaceae. In: Mori, S.A.; Cremers, G.; Gracie, C.A.; de Granville, J.J.; Heald, S.V.; Hoff, M. \& Mitchell, J.D. (eds.). Guide to the vascular plants of Central French Guiana 2. Memoirs of the New York Botanical Garden 76: 484-510.

Kubitzki, K. 1985. The dispersal of forest plants. In: Prance, G.T. \& Lovejoy, T.E. (eds.). Key environments - Amazonia. Pergamon Press, Oxford. Pp. 192-205.

Lewis, G.P. \& Owen, P.E. 1989. Legumes of the Ilha de Maracá. Royal Botanic Gardens, Kew. 95p.

Lima, H.C. 1990. Tribo Dalbergieae (Leguminosae Papilionoideae) - Morfologia dos frutos, sementes e plântulas e sua aplicação na sistemática. Arquivos do Jardim Botânico do Rio de Janeiro 30: 1-42.

Luckow, M. 2005. Mimoseae. In: Lewis, G.; Schrire, B.; Mackinder, B. \& Lock, M (eds.). Legumes of the World. The Royal Botanic Gardens, Kew. Pp. 163-183. 
Macbride, J.F. 1943. Flora of Peru: Leguminosae. Field Museum of Natural History, Botanical Series 13: 1-507.

Nzowa, L.K.; Teponno, R.B.; Tapondjou, L.A.; Verotta, L.; Liao, Z.; Graham, D.; Zink, M.-C. \& Barboni, L. 2013. Two new tryptophan derivatives from the seed kernels of Entada rheedei: effects on cell viability and HIV infectivity. Fitoterapia 87: 37-42.

Pounden, E.; Greene, D.F.; Quesada, M. \& Contreras Sánchez, J.M. 2008. The effect of collisions with vegetation elements on the dispersal of winged and plumed seeds. Journal of Ecology 96: 591-598.

Procópio, L.C.; Hopkins, M.J.G.; Pennington, T.D.; Vieira, M.G.G. \& Rico, L. 1999. Leguminosae: Mimosoideae. In: Ribeiro, J.E.L.S.; Hopkins, M.J.G.; Vicentini, A.; Sothers, C.A.; Costa, M.A.S.; Brito, J.M.; Souza, M.A.; Martins, L.H.P.; Lohmann, L.G.; Assunção, P.A.C.L.; Pereira, E.C.; Silva, C.F.; Mesquita, M.R. \& Procópio, L.C. Flora da Reserva Ducke: guia de identificação das plantas vasculares de uma floresta de terra-firme na Amazônia Central. INPA, Manaus. Pp. 362-381.

Rodrigues, R.S. 2015a. Note on the seed morphology of Entada polyphylla (Leguminosae, Mimosoideae) and its taxonomic significance in E. sect. Entadopsis. Boletim do Museu Integrado de Roraima 9: 8-11.

Rodrigues, R.S. 2015b. Are seedlings diagnostic in Neotropical Entada (Leguminosae)? Seedling morphology supports the reinstatement of Entada polyphylla. Phytotaxa 220: 287-294.

Rodrigues, R.S.; Feitoza, G.V. \& Flores, A.S. 2014. Taxonomic relevance of seed and seedling morphology in two Amazonian species of Entada (Leguminosae). Acta Amazonica 44: 19-24.

Rodrigues, R.S. \& Flores, A.S. 2012. A new combination in Entada (Leguminosae) from Roraima, Brazil. Phytotaxa 39: 47-50.

Priya, K.S.V. \& Rao, J.V.S. 2008. Exploration of tribal knowledge of Entada pursaetha DC: an endangered gigantic medicinal legume in Eastern Ghats. Ethnobotanical Leaflets 12: 36-43.

Woodson, R.E. \& Schery, R.W. 1950. Flora of Panama. Leguminosae. Annals of the Missouri Botanical Garden 37: 184-314.

Zheng, T.; Shu, G.; Yang, Z.; Mo, S.; Zhao, Y. \& Mei, Z. 2012. Antidiabetic effect of total saponins from Entada phaseoloides (L.) Merr. in type 2 diabetic rats. Journal of Ethnopharmacology 139: 814-821. 